\title{
Validation of the Chinese Dimensional Anhedonia Rating Scale in Depressed Patients in Hong Kong
}

\author{
Edgar Wing-ka Ching 1 , Tin Po Chiang², Jessica O. Y. Wong², Bonnie W. M. Siu², Koi Man Cheng², \\ Simon S. Y. Lui ${ }^{3}$, and Eric F. C. Cheung ${ }^{4}$ \\ 1Department of Psychiatry, United Christian Hospital, Hong Kong SAR, PR China \\ ${ }^{2}$ Castle Peak Hospital, Hong Kong SAR, PR China \\ ${ }^{3}$ Department of Psychiatry, The University of Hong Kong, Hong Kong SAR, PR China \\ ${ }^{4}$ Kwong Wah Hospital, Hong Kong SAR, PR China
}

\begin{abstract}
To better understand and gauge the severity of anhedonia, the Dimensional Anhedonia Rating Scale (DARS) was developed which focuses on assessing the four pleasure domains of anhedonia. Lacking any Asian data in the original study, a Chinese version of the DARS (C-DARS) was evaluated in this study. The scale was developed by backward and forward translations and reviewed by an expert panel and a focus group. One hundred fifty-one depressed patients were recruited. The internal consistency and test-retest reliability were confirmed (McDonald's $\omega=.82$ ); a confirmatory factor analysis showed a second-order model with adequate fit (RMSEA $=.078, C F I=.945)$. Concurrent validity was examined by the correlations with the Chinese version of the Snaith-Hamilton Pleasure Scale $(r=-.72$, $p<.001)$, while discriminant validity was examined with the Hamilton Depression Rating Scale $(r=-.34, p<.001)$. The C-DARS was shown to be a psychometrically sound and valid measure of anhedonia severity ready for clinical use.
\end{abstract}

Keywords: anhedonia, depression, China, psychometrics, SHAPS, HAMD, adults

\section{Defining Anhedonia}

Anhedonia, a term coined by Ribot (1896), refers to the inability to experience pleasure. Being a pathological construct across diagnoses, anhedonia is observed in depression (Feighner et al., 1972), schizophrenia (Andreasen, 1982), substance abuse disorder (Gawin \& Kleber, 1986), and post-traumatic stress disorder (Litz, 1992). The construct was later expanded into two facets: consummatory and anticipatory anhedonia (Klein, 1987) or based on the type of pleasure (Meehl, 1962), namely, the physical anhedonia, the absence of pleasure from physical and sensory experience (Shankman et al., 2010), and social anhedonia, the incapacity to experience interpersonal pleasure (Pelizza \& Ferrari, 2009). It bears great clinical significance in the association with poor outcome in depressed patients (Spijker et al., 2001). Forty percent of patients with major depressive disorder (MDD) were found to have clinically significant anhedonia (Pelizza et al., 2012). Anhedonia was also found to be one of the most common residual symptoms after cognitive therapy (Taylor et al., 2010). Treatment studies have isolated anhedonia as the core symptom that predicts treatment resistance (Downar et al., 2014; Uher et al., 2012, 2008; Vrieze et al., 2014), while a regression study has found that anhedonia is correlated with poor psychosocial functioning (Vinckier et al., 2017).

\section{Current Instruments in Assessing Anhedonia}

Various instruments have been developed to assess anhedonia in clinical settings. One of the first scales was the Scales for Physical and Social Anhedonia, which was later divided into the Revised Chapman Physical Anhedonia Scale (CPAS) and the Chapman Social Anhedonia Scale (CSAS; Chapman et al., 1976). However, the CPAS and CSAS measure trait anhedonia without any temporal consideration ("in general"). Subsequent scales such as the Fawcett-Clerk Pleasure Capacity Scale (Fawcett et al., 1983) and the Snaith-Hamilton Pleasure Scale (SHAPS; Snaith et al., 1995) only measure consummatory anhedonia but not its anticipatory counterpart. The Temporal Experience of Pleasure Scale (TEPS; Gard et al., 2006) was developed to assess only physical anhedonia but not social anhedonia. The Anticipatory and Consummatory 
Interpersonal Pleasure Scale (Gooding \& Pflum, 2014a, 2014b) focuses mainly on social anhedonia and shows good correlations with both anticipatory and consummatory subscales of the TEPS. Recently, the Dimensional Anhedonia Rating Scale (DARS; Rizvi et al., 2015) was developed to assess both physical and social anhedonia, and across four reward domains.

\section{Psychometric Properties of the DARS}

Rizvi et al. (2015) developed the self-reporting DARS by generating items assessing four components of anhedonia (interest, motivation, effort, and pleasure) of four reward domains (pastimes/hobbies, food and drink, social activities, and sensory experience), a categorization upon selection of items suggested by the general public in Britain of all social classes during development of the SHAPS by Snaith et al. (1995). In the first part of the study by Rizvi et al. (2015), the participants were required to provide at least two of their own examples of rewarding activities/ foods for each pleasure domain, which helped to generalize the scale for use in different cultures. Each component of anhedonia (interest, motivation, effort, and pleasure) of the domain was assessed with an item, with the exception in the sensory experience domains where an extra item was set on assessing the effort. They were then asked to rate the items with five response categories, with a lower score corresponding to a higher level of anhedonia. The scale was cross-validated in both nonclinical and clinical samples in the later part of the study, showing good psychometric properties (Rizvi et al., 2015). A recently published Spanish adaptation of the scale also confirmed the four-factor structure with factor analysis, the reliability with high internal consistency (Cronbach's $\alpha=.92$ ), and convergent validity with significant correlation with SHAPS ( $r=.507, p=<.001$; Arrua-Duarte et al., 2019). However, test-retest reliability was not assessed in the original study nor in the Spanish adaptation, and the applicability of the scale in Asian depressed subjects has never been examined before. The aim of this study was thus to translate and validate the Chinese version of the DARS (C-DARS) in Hong Kong. As the scale required the participants to name their own interests and score accordingly, slight cultural adaptation of the scale should suffice.

\section{Methods}

This study was divided into two parts: (1) the translation and cultural evaluation of the DARS in Chinese and (2) psychometric evaluation of the C-DARS. Approval was obtained from Dr. Sakina Rizvi, the original author of the DARS, for conducting the validation of the Chinese version of DARS in Hong Kong. This study was approved by the Clinical and Research Ethics Committee of the New Territories West Cluster of the Hospital Authority of Hong Kong.

\section{Translation and Cultural Evaluation}

The original English version of the DARS and the example of activities and experiences were translated into Chinese by the joint collaboration of a bilingual psychiatrist and an independent professional translator who is proficient in both languages with no medical background. It was then back-translated into English by the joint effort of another psychiatrist and professional translator again. The original author, the author of this study, the first translator, and a specialist psychiatrist compared the original English version and the back-translated version. Amendments were made to the Chinese version until the back-translated version was comparable with the original English version. The first draft of the C-DARS was then evaluated by an expert panel consisting of five psychiatrists, two nurses, two occupational therapists, and two clinical psychologists using a 5-point Likert scale to rate each item on its relevance and representativeness. They were also asked to offer suggestions for improving every item. The scale was later assessed by a focus group that comprised two patients with depression, two nurses, and allied health care professional, including two medical social workers and an occupational therapist, which focuses on the acceptability of the questionnaire. The concept of anhedonia and depression and the purpose of this study were introduced before the semistructured interview was conducted. All conversations were recorded electronically, and the transcript was reviewed by the author.

\section{Recruitment}

Participants were recruited from a psychiatric outpatient clinic in Hong Kong. Eligible patients must be of ethnic Chinese, aged 18-64 years, and had a history of DSM-IV diagnosis of MDD. We excluded patients who did not read Chinese, were unable to provide informed consents, and were comorbid with other Axis I diagnosis, with major physical illness, or with an Axis II diagnosis. After obtaining written consent from the participants, they were interviewed in person using the Chinese Bilingual version of the Structured Clinical Interview for DSM-IV-TR Axis I Disorder, Research Version, Patient Edition (CB-SCID-I/P). 
The participants were assessed with C-DARS, a 17-item self-report assessment tool assessing the four domains of anhedonia, namely, hobbies/pastime, food and drink, social activities, and sensory experience, as discussed before; SHAPS, a 14-item self-report questionnaire tapping onto the hedonic capacity with high scores corresponding to higher level of anhedonia; and finally, the Hamilton Depression Rating Scale (HAMD), which is a 21-item scale focusing on the severity of depression. Depression severity, measured by HAMD, was chosen for exploring the discriminant validity under the premise that depression and anhedonia are distinct albeit similar concepts, evidenced by anhedonia being refractory to the conventional treatment for depression (Nutt et al., 2007) and anhedonia being recognized as a transdiagnostic entity in a recent review (Husain \& Roiser, 2018). Participants were asked to complete the C-DARS again in 2- to 4-week time for assessing the test-retest reliability of the scale.

\section{Psychometric Evaluation}

The Mcdonald's $\omega$ coefficient was used to determine the internal consistency of the scale. Test-retest reliability was assessed with the Pearson correlation coefficient. The Spearman's correlation coefficient between the C-DARS and the SHAPS was expected to be high $(>0.7$; Streiner, 1993) to demonstrate the concurrent validity of the scale and low with HAMD to demonstrate the discriminant validity. Confirmatory factor analysis (CFA) was employed to examine the underlying latent components of the items in the scale. The data were analyzed using SPSS (version 24.0). CFA was done using $\mathrm{R}$ (version 4.0.3). The diagram of CFA was generated with Onyx (version 1.0-1026).

\section{Results}

\section{Recruitment}

A total of 4,229 patients were identified, while 704 patients were randomly selected. Seventy-three patients were found to have a change in diagnoses listed in the exclusion criteria; 409 patients suffered from acute or chronic medical conditions. In the end, 222 patients were identified to participate in this study. Among them, 28 patients were lost to follow-up, 33 refused to take part, and 10 were excluded after the interview. Finally, 151 participants were recruited in the validation study. Seventy-one nonparticipants were compared with the participants in terms of demographics of sex and age, and they did not differ significantly. The sociodemographic data and clinical characteristics of the participants are listed in Table 1, while the means and SD of the scores on C-DARS are listed in Table 2.

Table 1. Sociodemographic and clinical characteristics of participants

\begin{tabular}{|c|c|c|c|c|c|}
\hline Characteristics & $N$ & $\%$ & M & $S D$ & $95 \% \mathrm{Cl}$ \\
\hline \multicolumn{6}{|l|}{ Gender } \\
\hline Female & 112 & 74.2 & & & \\
\hline Male & 39 & 25.8 & & & \\
\hline Age & & & 45 & 10.3 & {$[43.3,46.7]$} \\
\hline \multicolumn{6}{|l|}{ Marital status } \\
\hline Single & 30 & 19.9 & & & \\
\hline Married & 73 & 48.3 & & & \\
\hline Divorced & 44 & 29.1 & & & \\
\hline Widowed & 4 & 2.65 & & & \\
\hline \multicolumn{6}{|l|}{ Educational level } \\
\hline Primary or less & 28 & 18.5 & & & \\
\hline Secondary & 100 & 66.2 & & & \\
\hline Tertiary or above & 23 & 15.2 & & & \\
\hline \multicolumn{6}{|l|}{ Employment status } \\
\hline Full-time & 48 & 31.8 & & & \\
\hline Part-time & 24 & 15.9 & & & \\
\hline Housewife & 43 & 28.5 & & & \\
\hline Retired & 7 & 4.64 & & & \\
\hline Unemployed & 29 & 19.2 & & & \\
\hline Age of onset of depression & & & 36 & 10.2 & {$[34.6,37.9$} \\
\hline Duration of illness & & & 8.8 & 6.9 & {$[7.68,9.91]$} \\
\hline \multicolumn{6}{|l|}{ Diagnosis } \\
\hline Mild depressive episode & 36 & 23.8 & & & \\
\hline $\begin{array}{l}\text { Moderate depressive } \\
\text { episode }\end{array}$ & 63 & 41.7 & & & \\
\hline Severe depressive episode & 15 & 9.93 & & & \\
\hline $\begin{array}{l}\text { Recurrent depressive } \\
\text { disorder, current episode } \\
\text { mild }\end{array}$ & 12 & 7.95 & & & \\
\hline $\begin{array}{l}\text { Recurrent depressive } \\
\text { disorder, current episode } \\
\text { moderate }\end{array}$ & 12 & 7.95 & & & \\
\hline $\begin{array}{l}\text { Recurrent depressive } \\
\text { disorder, current episode } \\
\text { severe }\end{array}$ & 3 & 1.99 & & & \\
\hline Remitted depression & 10 & 6.62 & & & \\
\hline \multicolumn{6}{|l|}{ On number of medication } \\
\hline Drug-free & 9 & 5.96 & & & \\
\hline 1 & 88 & 58.3 & & & \\
\hline 2 & 41 & 27.2 & & & \\
\hline 3 & 11 & 7.28 & & & \\
\hline 4 & 2 & 1.32 & & & \\
\hline
\end{tabular}

Note. $N=151$ 
Table 2. $M, S D$, and $95 \% \mathrm{Cls}$ of the C-DARS total and subscale scores

\begin{tabular}{lccc}
\hline C-DARS & $M$ & $S D$ & $95 \% \mathrm{Cl}$ \\
\hline Total score & 32.1 & 13.9 & {$[29.8,34.3]$} \\
Pastimes/Hobbies & 7.73 & 4.28 & {$[7.04,8.42]$} \\
Food and Drink & 8.29 & 3.73 & {$[7.69,8.89]$} \\
Social Activities & 6.11 & 4.31 & {$[5.42,6.80]$} \\
Sensory Experiences & 9.92 & 5.15 & {$[9.09,10.8]$} \\
\hline
\end{tabular}

Note. C-DARS = Chinese version of the Dimensional Anhedonia Rating Scale.

\section{Reliability}

\section{Internal Consistency}

The McDonald's $\omega$ of the total C-DARS was .82, while that of the subscales ranged from .86 to .92, as shown in Table 3. The Average interitem correlation (AIC) of the total scale was .45 and .60 to .76 for the subscales.

\section{Test-Retest Reliability}

Forty-five participants were randomly selected and administered the C-DARS again after 2 to 4 weeks. The average number of days between the first assessment and the reassessment with C-DARS was 21.0. Thirty-seven of them completed the C-DARS (response rate is $83 \%$ ). The test-retest reliability for the total score of the C-DARS was demonstrated with a correlation coefficient of .72, with the lowest correlation seen in the Food and Drink subscale of .40 , as shown in Table 4.

\section{Validity}

\section{Content Validity}

The content validity of the C-DARS was established after evaluation by an expert panel, revealing a high degree of relevance and representativeness of the C-DARS (agreement of $60-100 \%)$. There was concern over Q5 in the Food and Drink subscale, as the readily accessible restaurants and food in Hong Kong may render the item inappropriate. The wordings of two questions $(\mathrm{Q} 10$ and

Table 3. Internal consistency of the C-DARS total and subscales

\begin{tabular}{lcc}
\hline C-DARS & McDonald's $\omega$ & AIC \\
\hline Total score & .82 & .45 \\
Pastimes/Hobbies & .92 & .76 \\
Food and Drink & .86 & .60 \\
Social Activities & .90 & .68 \\
Sensory Experiences & .92 & .71 \\
\hline
\end{tabular}

Note. $N=151$. AIC = average interitem correlation, C-DARS = Chinese version of the Dimensional Anhedonia Rating Scale.
Q11) were modified for better clarity and fluency in delivery, as shown in Table 5. Culturally appropriate examples of activities were introduced for reference. In the focus group discussion, the issues raised could be categorized into the objectivity of the items, use of number coding of response instead of bullet point, use of slang words, and suggestion for clearer instructions. Fine adjustment to the translations and number coding were introduced to the questionnaire. During the discussion, the participants remarked that the C-DARS could be accepted as an anhedonia rating scale for its easy comprehensibility indicating satisfactory face validity.

\section{Concurrent Validity}

The relationship between the scores of C-DARS and the scores of the SHAPS was investigated using the Spearman's correlation analysis and showed high negative correlation (Spearman's $r=-.72, p<.001$ ). In addition, subscales of the C-DARS also demonstrated moderate correlation $(r s=-.45$ to $-.63, p s<.001)$, as demonstrated in Table 6.

\section{Structural Validity Evidence}

The 17 items of the C-DARS were subjected to CFA. A fourfactor solution yielded a normed fit index (NFI) of .894, a goodness of fit index (GFI) of .859, a CFI of .945, and a RMSEA of .078. All these indices suggested an adequate fit of the model (Schermelleh-Engel et al., 2003), confirming the structure and latent variables. The standardized factor loadings of the CFA are shown in Figure 1.

In addition, Spearman's correlations between the subscale scores and the C-DARS total scores were calculated. As shown in Table 7, the correlations between the C-DARS total score and the subscale scores were high $(r=0.76-0.83)$. However, the correlations between the four subscales were moderate $(r=0.43-0.60)$, indicating that the subscales were related to each other and were not redundant.

\section{Discriminant Validity}

The correlation of the C-DARS total score with the HAMD score $(r=-.34, p<.001)$ was low, so are those between the subscales with the HAMD, as shown in Table $6(r s=-.22$ to $-.44, p s<.001$ except for the Food and Drink subscale). The correlational strength (coefficient) between the C-DARS and HAMD total scores $(r=-.34, p<.001)$ was less than that between the C-DARS and the SHAPS total scores 
Table 4. Test-retest reliability of the C-DARS total and subscales

\begin{tabular}{|c|c|c|c|c|c|c|c|c|}
\hline \multirow[b]{2}{*}{ C-DARS } & \multicolumn{3}{|c|}{ First test score } & \multicolumn{3}{|c|}{ Retest score } & \multirow[b]{2}{*}{$r$} & \multirow[b]{2}{*}{$p$} \\
\hline & M & $S D$ & $95 \% \mathrm{Cl}$ & M & $S D$ & $95 \% \mathrm{Cl}$ & & \\
\hline Total score & 34.7 & 10.8 & {$[31.1,38.3]$} & 37.3 & 8.84 & {$[34.4,40.2]$} & .72 & $<.001$ \\
\hline Hobbies & 9.51 & 2.84 & {$[9.57,10.5]$} & 9.54 & 3.48 & {$[8.38,10.7]$} & .60 & $<.001$ \\
\hline Food and Drink & 8.62 & 3.03 & {$[7.61,9.63]$} & 9.68 & 2.63 & {$[8.80,10.6]$} & .40 & .015 \\
\hline Social Activities & 6.46 & 3.72 & {$[5.22,7.70]$} & 7.35 & 3.07 & {$[6.33,8.37]$} & .70 & $<.001$ \\
\hline Sensory Experiences & 10.1 & 4.95 & {$[8.43,11.7]$} & 10.7 & 4.00 & {$[9.39,12.1]$} & .72 & $<.001$ \\
\hline
\end{tabular}

$(r=-.72, p<.001)$. The Social Activities subscale of the C-DARS had the highest correlation with the HAMD $(r=-.44, p<.001)$.

Finally, correlation analysis between the sociodemographic variables (including age and duration of illness) and C-DARS total and subscale scores was done and demonstrated a very weak correlation between age and C-DARS total score $(r=.18, p=.031)$ and between duration of illness and Sensory Experience subscale $(r=.16$, $p=.048)$, as shown in Table 6.

\section{Discussion}

\section{Psychometric Properties of the C-DARS}

The C-DARS had an excellent internal consistency with a McDonald's $\omega$ comparable to the Cronbach's $\alpha$ found in the original study in the patient sample (Rizvi et al., 2015) and the Spanish adaptation study (Arrua-Duarte et al., 2019). The $\omega$ coefficients of the subscales were also comparable with the $\alpha$ coefficients obtained in the clinical sample of the original study and Spanish study. The AICs of the subscales were high, indicative of small bandwidth of the construct captured by the scale (Lyons-Thomas, 2014). This is frequently encountered in studies of anhedonia due to the subtlety of the differences between the components (namely, interest, motivation, effort, and pleasure; Gooding \& Pflum, 2014a, 2014b; Rizvi et al., 2015).

The correlation coefficient of the first and retest samples was comparable with the ICC of the Chinese version of SHAPS ( $r=.64, p<.001$; Liu et al., 2012). The correlation coefficients of the total C-DARS, the Pastimes/Hobbies subscale, the Social Activities subscale, and the Sensory Experiences between the first and retest results are indicative of fair to good reliability.

The CFA confirmed the four-factor structure of the scale and was in line with the demarcation as suggested by the original author to interest/hobby, food and drink, social activities, and sensory experience, also shown in the
Spanish study. The interfactor correlations of the subscale were moderate, while the correlation between the subscales and the total score was high. This demonstrates that the subscales cover different aspects of anhedonia while sharing a common theme and confirms the structural validity of C-DARS in assessing different facets of anhedonia in depressed patients. It underpins the benefit of the C-DARS over other scale with single-factor structure such as the SHAPS (Franken et al., 2007; Liu et al., 2012; Snaith et al., 1995).

The concurrent validity of the C-DARS was evinced by the significant negative correlations between the scores of the C-DARS and the SHAPS, which is compatible with the original study by Rizvi et al. (2015) and higher than observed in the Spanish study. The Food and Drink subscale again fared worse than other subscales, which was also observed in the original study with the clinical and nonclinical samples. The participants in this study had moderate severity of depression, while the sample in the original study suffered more severe type of depression in view of their high Center for Epidemiological Studies-Depression (CESD) score. Finally, the Spanish study included a heterogeneous group of patients of diagnoses ranging from psychoses to substance abuse disorder to mood disorder. This is consistent with the speculation that with increasing severity of depression, a more general dampening of reward responsivity may be observed across all components (including interest, motivation, effort, and pleasure) and reward domains, thus resulting in better agreement among the subscales.

Discriminant validity was demonstrated by the low correlations between the scores of the C-DARS and the HAMD, which is similar to the correlation coefficient between the DARS and the CESD scores in the original study (Rizvi et al., 2015). The result is similar to that

Table 5. Modification to the Chinese wordings of the C-DARS according to the expert panel

\begin{tabular}{lll}
\hline & \multicolumn{1}{c}{ Original version } & \multicolumn{1}{c}{ Modified version } \\
\hline Q10 & 我會有興趣做些涉及其他人的事情 & 我會有興趣參與群體活動 \\
Q11 & 我會是這些活動(社交活動)的策劃人 & 我會參與策劃這些活動 \\
\hline
\end{tabular}


Table 6. Correlation analysis of the C-DARS total and subscale with SHAPS, HAMD, age, and duration of illness

\begin{tabular}{|c|c|c|c|c|c|c|c|c|c|c|}
\hline \multirow[b]{2}{*}{ Variables } & \multicolumn{2}{|c|}{ SHAPS } & \multicolumn{2}{|c|}{ HAMD } & \multicolumn{2}{|c|}{ Age } & \multicolumn{2}{|c|}{ Gender } & \multicolumn{2}{|c|}{ Duration of illness } \\
\hline & $r$ & $p$ & $r$ & $p$ & $r$ & $p$ & $r$ & $p$ & $r$ & $p$ \\
\hline C-DARS total & -.72 & $<.001$ & -.34 & $<.001$ & .18 & .031 & -.08 & .357 & .084 & .303 \\
\hline Pastimes/Hobbies & -.63 & $<.001$ & -.39 & $<.001$ & .13 & .101 & -.03 & .716 & .10 & .238 \\
\hline Food and Drink & -.45 & $<.001$ & -.02 & .98 & .10 & .231 & -.10 & .255 & -.05 & .554 \\
\hline Social Activities & -.60 & $<.001$ & -.44 & $<.001$ & .12 & .162 & -.05 & .565 & .01 & .903 \\
\hline Sensory Experiences & -.60 & $<.001$ & -.22 & $<.001$ & .14 & .091 & -.07 & .410 & .16 & .048 \\
\hline
\end{tabular}

Note. $N=151$. C-DARS $=$ Chinese version of the Dimensional Anhedonia Rating Scale, HAMD = Hamilton Depression Rating Scale, SHAPS = Snaith-Hamilton Pleasure Scale. Data analyzed by the Spearman's rho correlation coefficient.

between the SHAPS and the Beck Depression Inventory in Chinese clinical samples by Liu et al. (2012). To the best of our knowledge, this is the first study examining the satisfactory discriminant validity of the DARS with clinicianrated depression scale.

As stated above, the Food and Drink subscale was noted to have poor correlation with the SHAPS and the HAMD. In the original study, the Food and Drink subscale was also found to have lower correlation with the SHAPS than other subscales. Furthermore, question 5 was noted to have the lowest regression coefficient in the factor analysis. This is consistent with the concerns of the expert panel that the question may not truly reflect physical anhedonia toward food in this locality. The subscale was also noted to be unstable over time, evidenced by its worst test-retest reliability among all subscales. However, the exclusion of the item showed no significant difference in the factor analysis, and thus, it was retained.

\section{Implications on Clinical Practice}

The C-DARS is an easy-to-use and acceptable self-report questionnaire to assess anhedonia severity in depressed patients across different pleasure domains, in contrast to previous scales. Early identification of patients with hedonic deficits would facilitate treatment planning, as studies have identified specific agents, such as adjunctive use of aripiprazole (Reimherr et al., 2010), agomelatine (Martinotti et al., 2012), and bupropion (Tomarken et al.,

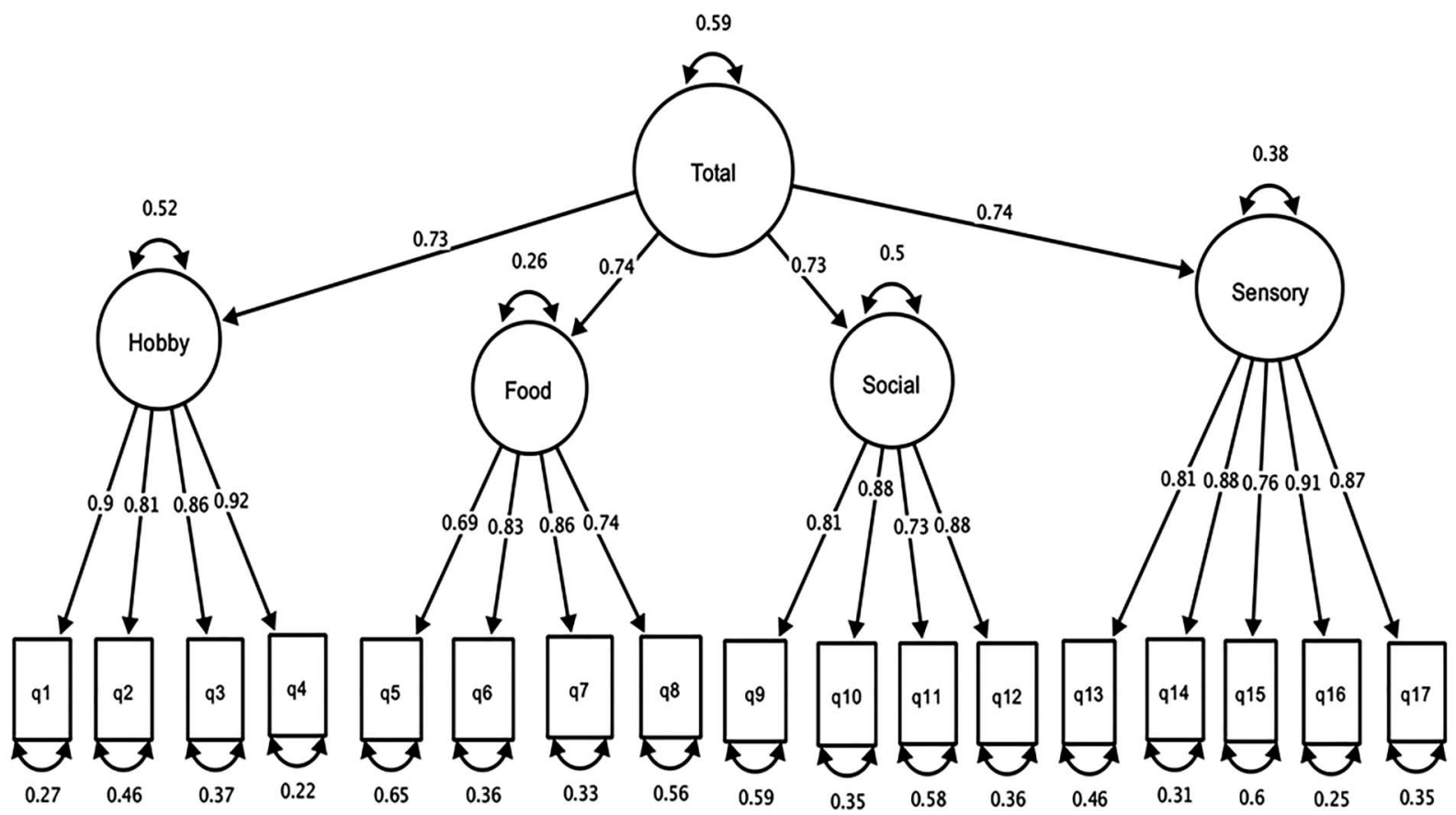

Figure 1. Model of CFA of C-DARS. All estimates are standardized. Rectangles represent observed variables (items in the C-DARS), and ellipses represent unobserved variables (latent variables). Double-headed arrows are a symbol for a correlation. Arrows pointing toward items are the variance of error term of the items. The values between latent variables are standardized regression weights. C-DARS = Chinese version of the Dimensional Anhedonia Rating Scale, CFA = confirmatory factor analysis. 
Table 7. Subscale-total score and interfactor correlations

\begin{tabular}{lcccc}
\hline Subscale & $\begin{array}{c}\text { C-DARS } \\
\text { total }\end{array}$ & Hobbies & $\begin{array}{c}\text { Food and } \\
\text { Drink }\end{array}$ & Social \\
\hline Hobbies & $.788^{\star \star}$ & & & \\
Food and Drink & $.760^{\star *}$ & $.456^{\star *}$ & & \\
Social Activities & $.794^{\star *}$ & $.597^{\star *}$ & $.427^{\star *}$ & \\
Sensory & $.826^{\star *}$ & $.462^{\star *}$ & $.588^{\star *}$ & $.499^{\star *}$ \\
Experiences & & & & \\
\hline
\end{tabular}

Note. $N=$ 151. C-DARS = Chinese version of the Dimensional Anhedonia Rating Scale. Data analyzed by the Spearman's rho correlation coefficient. ${ }^{\star \star} p<.001$.

2004), to be more effective in alleviating anhedonic symptoms. SSRI on the other hand would diminish neural response to reward stimuli in healthy subjects (McCabe et al., 2010) and fare worse in alleviating anhedonia in depressed patients (Yee et al., 2015). The neurostimulation study has also proposed a distinct depressive subtype with disrupted hedonic function and different response to treatment (Downar et al., 2014).

\section{Limitations}

Although the number of clinical subjects included in the study may be comparable to the original scale or the Spanish study, the statistical power of the study is still hampered by the small size. The sample size is below 250, which is suggested for arriving a stable correlation coefficient (Schönbrodt \& Perugini, 2013), although the current sample size is still sufficient to arrive at the statistically significant result (Bujang \& Baharum, 2016). This study also provides us with the first set of data on anhedonia of a cohort of Asian with depression. However, a substantial number of patients with acute or chronic medical illnesses were excluded from the study to avoid the confounding effect of physical illness when assessing the effort construct. As demonstrated by the Spanish study, the convergent validity of the scale was weaker in a heterogeneous group of patients (Arrua-Duarte et al., 2019). Thus, the disadvantage of a more controlled and specialized cohort of participants was made up for by an improved and more pronounced statistical result.

\section{Future Research Directions}

Future studies should include a larger sample, and the scale can also be validated in psychiatric patients with other diagnoses. A longitudinal study can be conducted to explore the sensitivity to change and the predictive validity of the C-DARS. Investigation into a cutoff value for the C-DARS should also be considered in future studies.

\section{References}

Andreasen, N. C. (1982). Negative symptoms in schizophrenia: Definition and reliability. Archives of General Psychiatry, 39(7), 784-788. https://doi.org/10.1001/archpsyc.1982.04290070020005

Arrua-Duarte, E., Migoya-Borja, M., Barrigón, M. L., Barahona, I., Delgado-Gomez, D., Courtet, P., Aroca, F., Rizvi, S. J., Kennedy, S. H., Quilty, L. C., \& Baca-García, E. (2019). Spanish adaptation of the Dimensional Anhedonia Rating Scale (DARS). Journal of Affective Disorders, 245, 702-707. https://doi.org/10.1016/j.jad.2018.11.040

Bujang, M. A., \& Baharum, N. (2016). Sample size guideline for correlation analysis. World Journal of Social Science Research, 3(1), 37-46. https://doi.org/10.22158/wjssr.v3n1p37

Chapman, L. J., Chapman, J. P., \& Raulin, M. L. (1976). Scales for physical and social anhedonia. Journal of Abnormal Psychology, 85(4), 374-382. https://doi.org/10.1037/0021-843X.85.4.374

Downar, J., Geraci, J., Salomons, T. V., Dunlop, K., Wheeler, S., McAndrews, M. P., Bakker, N., Blumberger, D. M., Daskalakis, Z. J., Kennedy, S. H., Flint, A. J., \& Giacobbe, P. (2014). Anhedonia and reward-circuit connectivity distinguish nonresponders from responders to dorsomedial prefrontal repetitive transcranial magnetic stimulation in major depression. Biological Psychiatry, 76(3), 176-185. https://doi.org/10.1016/j.biopsych.2013.10.026

Fawcett, J., Clark, D. C., Scheftner, W. A., \& Gibbons, R. D. (1983). Assessing anhedonia in psychiatric patients. Archives of General Psychiatry, 40(1), 79-84. https://doi.org/10.1001/archpsyc.1983. 01790010081010

Feighner, J. P., Robins, E., Guze, S. B., Woodruff, R. A., Winokur, G., \& Munoz, R. (1972). Diagnostic criteria for use in psychiatric Research. Archives of General Psychiatry, 26(1), 57-63. https:// doi.org/10.1001/archpsyc.1972.01750190059011

Franken, I. H. A., Rassin, E., \& Muris, P. (2007). The assessment of anhedonia in clinical and non-clinical populations: Further validation of the Snaith-Hamilton Pleasure Scale (SHAPS). Journal of Affective Disorders, 99(1-3), 83-89. https://doi.org/10.1016/j. jad.2006.08.020

Gard, D. E., Gard, M. G., Kring, A. M., \& John, O. P. (2006). Anticipatory and consummatory components of the experience of pleasure: $A$ scale development study. Journal of Research in Personality, 40(6), 1086-1102. https://doi.org/10.1016/j.jrp.2005.11.001

Gawin, F. H., \& Kleber, H. D. (1986). Abstinence symptomatology and psychiatric diagnosis in cocaine abusers: Clinical observations. Archives of General Psychiatry, 43(2), 107-113. https:// doi.org/10.1001/archpsyc.1986.01800020013003

Gooding, D. C., \& Pflum, M. J. (2014a). Further validation of the ACIPS as a measure of social hedonic response. Psychiatry Research, 215(3), 771-777. https://doi.org/10.1016/j.psychres.2013.11.009

Gooding, D. C., \& Pflum, M. J (2014b). The assessment of interpersonal pleasure: Introduction of the Anticipatory and Consummatory Interpersonal Pleasure Scale (ACIPS) and preliminary findings. Psychiatry Research, 215(1), 237-243. https://doi.org/10.1016/j.psychres.2013.10.012

Husain, M., \& Roiser, J. P. (2018). Neuroscience of apathy and anhedonia: A transdiagnostic approach. Nature Reviews Neuroscience, 19(8), 470-484. https://doi.org/10.1038/s41583-018-0029-9

Klein, D. F. (1987). Depression and anhedonia. In D. C. Clark \& J. Fawcett (Eds.), Anhedonia and affect deficit states. PMA Pub. Corp.

Litz, B. T. (1992). Emotional numbing in combat-related posttraumatic stress disorder: A critical review and reformulation. Clinical Psychology Review, 12(4), 417-432. https://doi.org/10. 1016/0272-7358(92)90125-R

Liu, W., Wang, L., Zhu, Y., Li, M., \& Chan, R. C. (2012). Clinical utility of the Snaith-Hamilton-Pleasure Scale in the Chinese settings. BMC Psychiatry, 12(1), 184. https://doi.org/10.1186/1471-244X-12-184 
Lyons-Thomas, J. (2014). Interscale correlations. In A. C. Michalos (Ed.), Encyclopedia of quality of life and well-being research (pp. 3352-3353). Springer. https://doi.org/10.1007/978-94-007-0753-5_1519

Martinotti, G., Sepede, G., Gambi, F., Dilorio, G., DeBerardis, D., DiNicola, M., Onofrj, M., Janiri, L., \& DiGiannantonio, M. (2012). Agomelatine versus venlafaxine $\mathrm{xr}$ in the treatment of anhedonia in major depressive disorder. Journal of Clinical Psychopharmacology, 32(4), 487-491. https://doi.org/10.1097/JCP.0b013e31825d6c25

McCabe, C., Mishor, Z., Cowen, P. J., \& Harmer, C. J. (2010). Diminished neural processing of aversive and rewarding stimuli during selective serotonin reuptake inhibitor treatment. Biological Psychiatry, 67(5), 439-445. https://doi.org/10.1016/j.biopsych.2009.11.001

Meehl, P. E. (1962). Schizotaxia, schizotypy, schizophrenia. American Psychologist, 17(12), 827-838. https://doi.org/10.1037/h0041029

Nutt, D., Demyttenaere, K., Janka, Z., Aarre, T., Bourin, M., Canonico, P. L., \& Stahl, S. (2007). The other face of depression, reduced positive affect: The role of catecholamines in causation and cure. Journal of Psychopharmacology, 21(5), 461-471. https://doi.org/10.1177/0269881106069938

Pelizza, L., \& Ferrari, A. (2009). Anhedonia in schizophrenia and major depression: State or trait? Annals of General Psychiatry, 8(1), 22. https://doi.org/10.1186/1744-859X-8-22

Pelizza, L., Pupo, S., \& Ferrari, A. (2012). Anhedonia in schizophrenia and major depression: State or trait? Review of the literature. Journal of Psychopathology, 18(2), 145-155. https://doi.org/10. 1186/1744-859X-8-22

Reimherr, F. W., Martin, M. L., Eudicone, J. M., Marchant, B. K., Tran, Q.-V., Pikalov, A., Marcus, R., Berman, R., \& Carlson, B. X. (2010). A pooled MADRS/IDS cross-correlation analysis. Journal of Clinical Psychopharmacology, 30(3), 300-305. https://doi. org/10.1097/JCP.0b013e3181db320f

Ribot, T. (1896). La psychologie des sentiments [The psychology of feelings]. Felix Arcan.

Rizvi, S. J., Quilty, L. C., Sproule, B. A., Cyriac, A., Michael Bagby, R., \& Kennedy, S. H. (2015). Development and validation of the Dimensional Anhedonia Rating Scale (DARS) in a community sample and individuals with major depression. Psychiatry Research, 229(1-2), 109-119. https://doi.org/10.1016/j.psychres.2015.07.062

Schermelleh-Engel, K., Moosbrugger, H., \& Müller, H. (2003). Evaluating the fit of structural equation models: Tests of significance and descriptive goodness-of-fit measures. Methods of Psychological Research Online, 8(2), 23-74.

Schönbrodt, F. D., \& Perugini, M. (2013). At what sample size do correlations stabilize? Journal of Research in Personality, 47(5), 609-612. https://doi.org/10.1016/j.jrp.2013.05.009

Shankman, S. A., Nelson, B. D., Harrow, M., \& Faull, R. (2010). Does physical anhedonia play a role in depression? A 20-year longitudinal study. Journal of Affective Disorders, 120(1-3), 170-176. https://doi.org/10.1016/j.jad.2009.05.002

Snaith, R. P., Hamilton, M., Morley, S., Humayan, A., Hargreaves, D., \& Trigwell, P. (1995). A scale for the assessment of hedonic tone. The Snaith-Hamilton Pleasure Scale. British Journal of Psychiatry, 167(1), 99-103. https://doi.org/10.1192/bjp.167.1.99

Spijker, J., Bijl, R. V, De Graaf, R., \& Nolen, W. A. (2001). Determinants of poor 1-year outcome of DSM-III-R major depression in the general population: Results of the Netherlands Mental Health Survey and Incidence Study (NEMESIS). Acta Psychiatrica Scandinavica, 103(2), 122-130. https://doi.org/10.1034/j.1600-0447.2001.103002122.x

Streiner, D. L. (1993). A checklist for evaluating the usefulness of rating scales. The Canadian Journal of Psychiatry. 38(2), 140-148. https://doi.org/10.1177/070674379303800214

Taylor, D. J., Walters, H. M., Vittengl, J. R., Krebaum, S., \& Jarrett, R. B. (2010). Which depressive symptoms remain after response to cognitive therapy of depression and predict relapse and recurrence? Journal of Affective Disorders, 123(1-3), 181-187. https://doi.org/10.1016/j.jad.2009.08.007
Tomarken, A. J., Dichter, G. S., Freid, C., Addington, S., \& Shelton, R. C. (2004). Assessing the effects of bupropion SR on mood dimensions of depression. Journal of Affective Disorders, 78(3), 235-241. https://doi.org/10.1016/S0165-0327(02)00306-3

Uher, R., Farmer, A, Maier, W., Rietschel, M., Hauser, J., Marusic, A., Mors, O., Elkin, A., Williamson, R. J., Schmael, C., Henigsberg, N., Perez, J., Mendlewicz, J., Janzing, J. G. E., Zobel, A., Skibinska, M., Kozel, D., Stamp, A. S., Bajs, M., ... Aitchison, K. J. (2008). Measuring depression: Comparison and integration of three scales in the GENDEP study. Psychological Medicine, 38(2), 289-300. https://doi.org/10.1017/S0033291707001730

Uher, R., Perlis, R. H., Henigsberg, N., Zobel, A., Rietschel, M., Mors, O., Hauser, J., Dernovsek, M. Z., Souery, D., Bajs, M., Maier, W., Aitchison, K. J., Farmer, A., \& McGuffin, P. (2012). Depression symptom dimensions as predictors of antidepressant treatment outcome: Replicable evidence for interest-activity symptoms. Psychological Medicine, 42(5), 967-980. https:// doi.org/10.1017/S0033291711001905

Vinckier, F., Gourion, D., \& Mouchabac, S. (2017). Anhedonia predicts poor psychosocial functioning: Results from a large cohort of patients treated for major depressive disorder by general practitioners. European Psychiatry, 44, 1-8. https://doi.org/10. 1016/j.eurpsy.2017.02.485

Vrieze, E., Demyttenaere, K., Bruffaerts, R., Hermans, D., Pizzagalli, D. A., Sienaert, P., Hompes, T., de Boer, P., Schmidt, M., \& Claes, S. (2014). Dimensions in major depressive disorder and their relevance for treatment outcome. Journal of Affective Disorders, 155(1), 35-41. https://doi.org/10.1016/j.jad.2013.10.020

Yee, A., Chin, S. C., bt Hashim, A. H., Harbajan Singh, M. K. A., Loh, H. S., Sulaiman, A. H., \& Ng, C. G. (2015). Anhedonia in depressed patients on treatment with selective serotonin reuptake inhibitor anti-depressant - a two-centered study in Malaysia. International Journal of Psychiatry in Clinical Practice, 19(3), 182-187. https://doi.org/10.3109/13651501.2015.1031139

\section{History}

Received July 7, 2020

Revision received June 16, 2021

Accepted June 16, 2021

Published online August 11, 2021

Section: Clinical Psychology

\section{Acknowledgments}

Dr. Lau Mei Suen Mandy, Dr. Mak Shun Chi Mercedes, Dr. Wong Hei Chung Jemima, Dr. Hon King Him Simon, Ms. Tang Eunice (translator), and Mr. Kenny Hui (translator) are greatly appreciated for their help and assistance. We report how we determined our sample size, all data exclusions, all manipulations, and all measures in the study.

\section{Funding}

There is no external funding for this manuscript.

\section{Open Data}

The data that support the findings of this study are available on request from the corresponding author. The data are not publicly available due to privacy restrictions.

\section{Edgar Wing-ka Ching}

Department of Psychiatry

United Christian Hospital

130 Hip Wo Street

Kwun Tong

Hong Kong SAR

PR China

cwk687@ha.org.hk 